\title{
Value of p53 and estrogen receptors immunohistochemical staining in endometrial carcinoma
}

\author{
Dejan Opric ${ }^{1}$, Amer Suskic ${ }^{2 *}$, Sanela Halilovic Suskic ${ }^{3}$, Gorana Nikolic ${ }^{1}$, Isidora Filipovic ${ }^{1}$
}

\begin{abstract}
${ }^{1}$ Department of Department Pathology, Medical Faculty University of Belgrade, Belgrade, Serbia
${ }^{2}$ Department of Gynecology and Obstetrics, Public Hospital Travnik, Travnik, Bosnia and Herzegovina

${ }^{3}$ Department of Internal Medicine, Public Hospital Travnik, Travnik, Bosnia and Herzegovina
\end{abstract}

Received: 14 October 2019

Accepted: 11 November 2019

\author{
*Correspondence: \\ Dr. Amer Suskic, \\ E-mail: amersuskic@yahoo.de
}

Copyright: () the author(s), publisher and licensee Medip Academy. This is an open-access article distributed under the terms of the Creative Commons Attribution Non-Commercial License, which permits unrestricted non-commercial use, distribution, and reproduction in any medium, provided the original work is properly cited.

\section{ABSTRACT}

Background: Since there are many articles dealing with estimating prognostic and diagnostic value of ER and p53, using different, usually complex ICH interpretation methods, we wanted to evaluate significance of p53 and ER ICH positivity in endometrial carcinoma, using easily applicable criteria that would help pathologists and clinicians to be sure in ICH findings noted in the report.

Methods: This paper deals with data of the patients treated for endometrial carcinoma in Public Hospitals in Travnik, gynecological department in the period from $1^{\text {st }}$ January 2013 to $1^{\text {st }}$ January 2019 . The study included 97 women with endometrial carcinoma, with ages ranging from 42 to 90 years (mean of 64 years). Sample consisted of 72 cases (74.2\%) of endometrioid and 25 cases $(25.8 \%)$ of non-endometrioid carcinoma.

Results: p53 expression was observed in $13.8 \%$ carcinomas of the endometrioid type and in $68 \%$ carcinomas of nonendometrioid type, while estrogen receptors were more frequently observed in tumors of the endometrioid type $(61 \%)$ in contrast to non-endometrioid type (28\%). Among 72 cases, those with grade I expressed estrogen receptors (26 out of 34 cases - 72\%) more frequently than those with grades II and III. Frequency of p53 positivity was significantly higher at higher grades (grade I - 5.8\%, grade II - 11.5\%, grade III - 71.4\%). Stage I carcinomas showed p53 staining less frequently $(22.2 \%)$ that carcinomas diagnosed at later stages $(31.5 \%)$.

Conclusions: Using $80 \%$ nuclei stained as threshold for p53 positivity, we concluded that p53 is marker of highgrade endometrial carcinomas: high grade endometrioid and non-endometrioid carcinomas. Using $1 \%$ of cells as threshold for ER positivity, we confirmed that ER are common in endometrioid type carcinoma, in contrast to nonendometrioid type. Although observed, higher frequency of ER in tumors with lower grade and stage was not statistically confirmed in our study population.

Keywords: Endometrial carcinoma, Estrogen receptors, Immunohistochemical staining, p53

\section{INTRODUCTION}

Endometrial carcinoma represents the most common female genital cancer in the US. From 2006, both incidence and death rate increased by about $1 \%$ and $2 \%$ per year, respectively. The average age of woman diagnosed with endometrial carcinoma is 60 , while it is uncommon in woman younger than $45 .{ }^{1}$ The differences in the epidemiology, presentation and biological behaviour of endometrial carcinoma suggest that there are two types of pathogenic diseases: type I endometrial carcinoma, also known as estrogen dependent or endometrioid type, and the type II, which is estrogen independent and non-endometrioid type. While type I 
tends to occur in younger perimenopausal women with hyperlipidemia, obesity, hyperestrogenism, anovulatory bleeding, infertility, late menopause, ovarian stromal hyperplasia and endometrial hyperplasia, type II endometrial carcinoma occurs in older postmenopausal women in absence of exogenous or endogenous hyperestrogenism and endometrial hyperplasia. ${ }^{2-4}$ Although type I endometrial carcinoma is remarkably more common, with type II carcinoma representing only $10-20 \%$ of cases, type II has worse prognosis and it is responsible for $40 \%$ of deaths from the disease..$^{2,5}$

PTEN gene is frequently altered in type I carcinomas, while type II carcinomas usually show overexpression of p53. Mutations or increased expression of the p53 tumor suppressor gene occurs in $10-48 \%$ of endometrial carcinoma, in poorly differentiated carcinoma with no steroid receptors, diagnosed in advanced stage with poor prognosis. ${ }^{6,7}$ Considering the fact that a mutation of the p53 gene is absent in endometrial hyperplasia, it is believed that it represents a late event in the pathogenesis of endometrial carcinoma of endometrioid type. ${ }^{8,9}$ Antioncogene p53 mutations could be found in $45-85 \%$ of serous endometrial cancer, even in early stages. ${ }^{10}$ Carcinoma of endometrioid type contain receptors for estrogen and progesterone in contrast with nonendometrioid type which usually does not contain these receptors. Levels of estrogen receptors (ER) and progesterone receptors are high in hyperplastic endometrium and higher in endometrial hyperplasia without nuclear atypia than in atypical hyperplasia. ${ }^{11,12}$ Two different types of ER are known: ER $\alpha$ with 595 amino acids and ER $\beta$ with 530 amino acids. ER $\alpha$ gene is located on chromosome 6, ER $\beta$ gene on chromosome 14 , which indicates that there are two different receptors. ${ }^{13}$ The presence of estrogen receptors ER $\alpha$ is associated with low grade and early stage of the disease. ${ }^{14}$ Usefulness of ER status for treatment planning is controversial. ${ }^{10,15}$

Immunohistochemistry ( $\mathrm{ICH})$ is relatively simple and cheap method, routinely used in many laboratories. However, it is subjective method and inter-observer discrepancies may be great problem, especially when there are no strictly defined criteria for evaluation. When cut-off is defined as percentage of positive cells, rough estimation may pose a problem and enhance interobserver discrepancies, especially in research, but also in daily practice. There are many studies dealing with prognostic and/or diagnostic value of p53 and/or ER expression in endometrial cancer. However, there are difficulties in interpretating the results.

Increased p53 staining may be the result of the presence of mutant p53 protein that is more stable and has a longer half-life, so it is resiliant to degradation thus detectable, but it can also be consequence of stabilization of normal p53 due to overexpression in response to DNA damage. However, there is opinion that over expression of wildtype gene and presence of mutant p53 show different staining patterns and that diffuse nuclear staining in more than $80 \%$ of cells is indicative for presence of mutation. ${ }^{16,17}$

Determining ER status may be useful in treatment planning, but there is no clear cut-off above which tumor should be considered ER positive. Many studies are using scoring systems based on complex calculations and evaluation of both intensity and extent, which is complicated and prone to inter-observer variability. ${ }^{14,18-21}$ There are also studies considering this problem that do not specify method for determining positivity. ${ }^{22}$ TCGA reports $7.49 \%$ as threshold. However, for qualitative evaluation of breast carcinoma, it is recommended to consider positive sample with at least $1 \%$ of positive cells. $^{23}$

Since there are many articles dealing with estimating prognostic and diagnostic value of ER and p53, using different, usually complex ICH interpretation methods, we wanted to evaluate significance of p53 and ER ICH positivity in endometrial carcinoma, using easily applicable criteria that would help pathologists and clinicians to be sure in ICH findings noted in the report.

\section{METHODS}

This paper deals with data of the patients treated for endometrial carcinoma in Public Hospitals in Travnik, gynecological department, in the period from $1^{\text {st }}$ January 2013 to $1^{\text {st }}$ January 2019. The sample consisted of 97 women with endometrial carcinoma, with ages ranging from 42 to 90 years (mean of 64 years). The study included 97 patients with a diagnosis of endometrial carcinoma, according to the current TNM classification, in accordance with the classification of the International federation of gynecologists and obstetricians (FIGO). Patient sociodemographic data were obtained from medical records. Paraffin blocks of adenocarcinoma tissue, which were initially fixed in $10 \%$ formalin and then embedded in paraffin, were tissue was cut at $3 \mathrm{m \mu}$ and stained with hematoxylin and eosin (HE). The most representative histological sections underwent further IHC analysis.

The HE and IHC stained slides were examined by two younger pathologists, followed by confirmation by senior pathologist supervisor. Histopathological parameter included histological type of tumor (endometrioid and non-endometrioid), grade and stage. Histological type of tumor was determined according to WHO classification.

Histological grade of endometrial cancer was determined according to FIGO criteria, which are defined as follows: grade 1-less than 5\% of tumor is solid fields, grade 2- 6$50 \%$ of tumors is solid fields and grade 3-more than $50 \%$ of tumor is solid fields. Grade was assessed exclusively for endometrioid type carcinomas, as recommended by FIGO. ${ }^{24,25}$ Stage was determined using WHO and FIGO criteria. 
For the IHC staining, individual preparations are fixed in paraffin and cut at $3 \mu \mathrm{m}$. After deparaffinization, tissue was embedded in methanol with $0.3 \%$ hydroperoxyl acid for 30 minutes at room temperature, in order to block endogenous peroxidase activity. After antigen retrieval performed using citrate buffer (PH6) at temperature of 100 degrees of Celsius, incubation with primary Estrogen alpha and p53 antibodies was done. Antibody-antigen complexes were detected using DAB detection kit according to manufacturer's instructions. Negative controls were obtained by omitting the primary antibodies. The results were evaluated by microscopic examination. Slides with at least $80 \%$ nuclei stained with p53 were consider positive, as well slides with at least $1 \%$ of nuclei stained with ER.

\section{Statistical analysis}

Statistical analysis was performed using the SPSS software, version 22.0 (IBM Corporation, New York, NY, USA). Differences among samples were tested using $\mathrm{X} 2$ and Fisher test. $\mathrm{P}$ value was less than or equal to 0.05 was considered statistically significant.

\section{RESULTS}

The sample consisted of 97 women with endometrial carcinoma, with ages ranging from 42 to 90 years (mean of 64 years). There were 72 cases $(74.2 \%)$ of endometrioid carcinoma and 25 (25.8\%) nonendometrioid carcinoma (Figures 1 and 2).

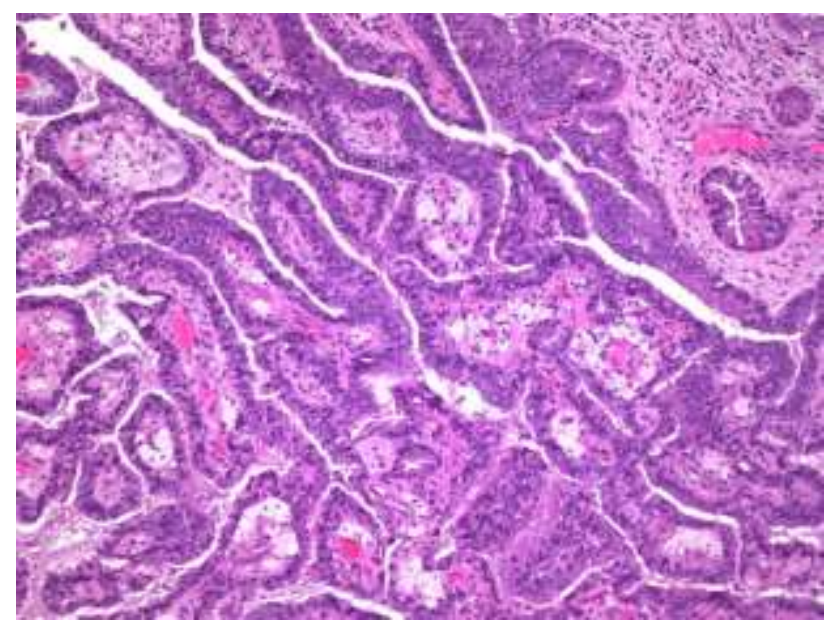

Figure 1: Endometrial carcinoma.

The majority of the patients with both endometrioid $(60 \%)$ and non-endometrioid $(52 \%)$ carcinoma were diagnosed in stage II, III et IV. In group of endometroid carcinoma, 29/72 (40\%) tumors were diagnosed at stage I, while $43 / 72(60 \%)$ tumors were presented at higher stages (stage II, III or IV). 12/25 (48\%) cases of nonendometrioid carcinoma were diagnoses at stage II, while $13 / 25(52 \%)$ non endometrioid carcinoma presented at higher stage (stage II, III or IV) (Table 1).

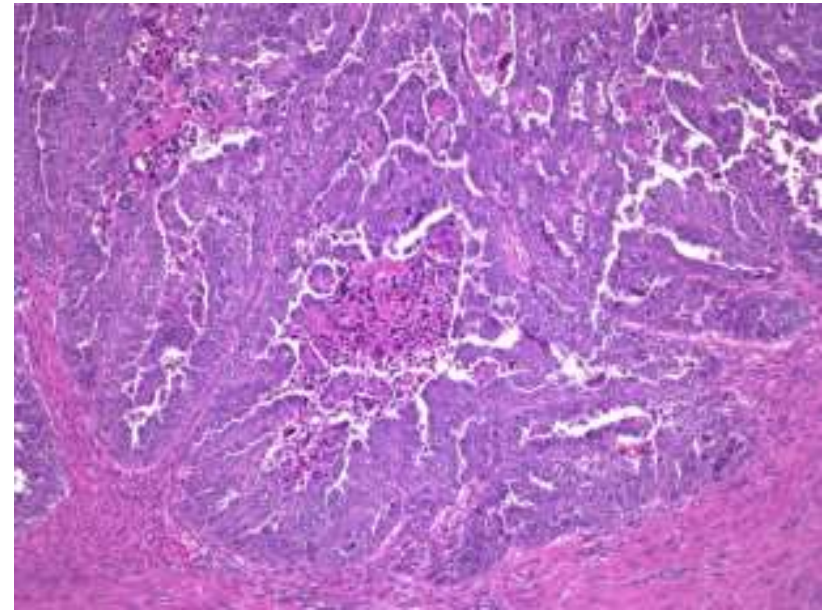

Figure 2: Non-endometrial carcinoma.

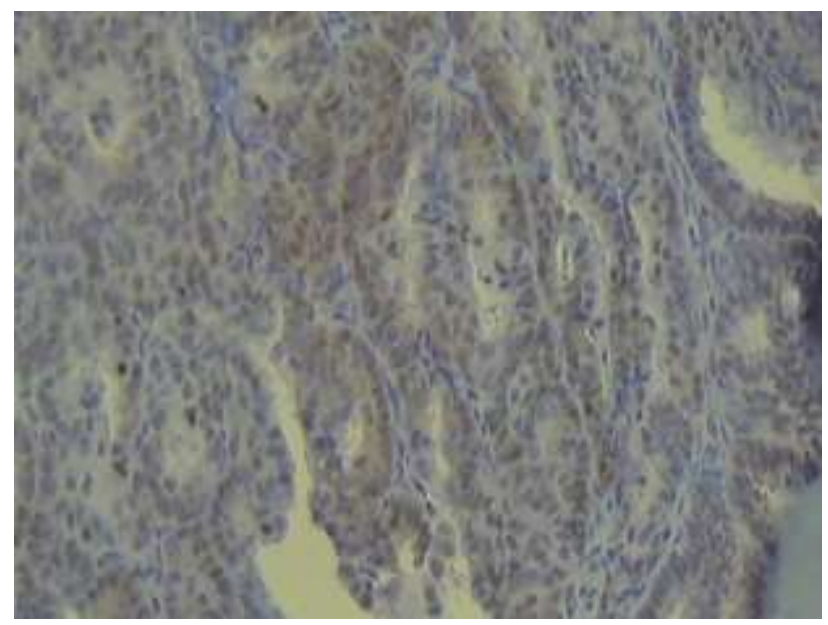

Figure 3: Positive immunohistochemical nuclear staining of p53.

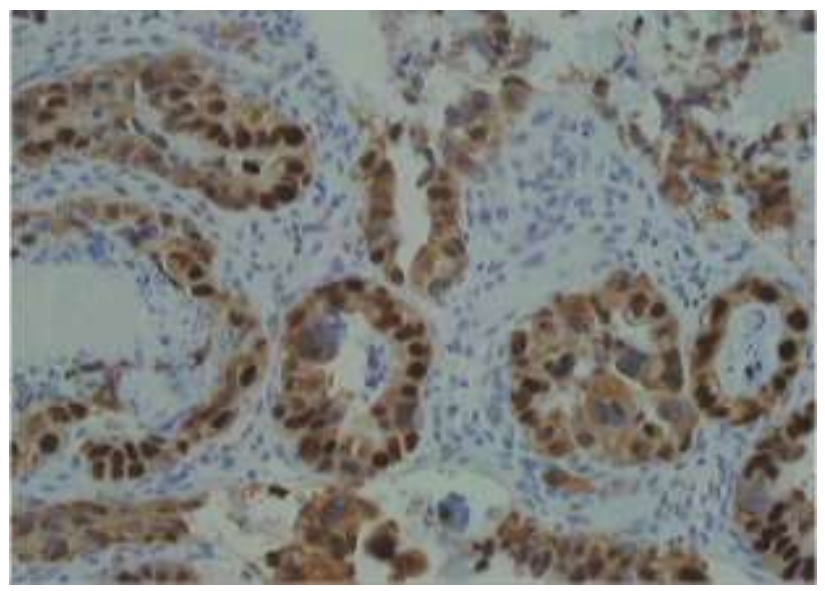

Figure 4: Nuclear estrogen receptor immunostaining in endometrioid adenocarcinoma.

Markers and histological types: p53 expression was observed in $10(13.8 \%)$ carcinomas of the endometrioid type and in $17(68 \%)$ carcinomas of non-endometrioid type (Figure 3). The estrogen receptors were more 
frequently observed in tumors of the endometrioid type: $44(61 \%)$ endometrioid type carcinoma showed ER staining in contrast to $7(28 \%)$ ER positive cases of the non-endometrioid type endometrial carcinoma (Figure 4) (Table 2).

Table 1: Stages and histological types of endometrial carcinoma specimens.

\begin{tabular}{|llll|}
\hline Stage & $\begin{array}{l}\text { Endometrioid } \\
\text { type n }(\%)\end{array}$ & $\begin{array}{l}\text { Non endometrioid } \\
\text { type n }(\%)\end{array}$ & $\begin{array}{l}\text { In } \\
\text { total }\end{array}$ \\
\hline I & $26(40 \%)$ & $10(40 \%)$ & 36 \\
\hline II. III. IV & $39(60 \%)$ & $15(60 \%)$ & 54 \\
\hline In total & $\mathbf{6 5}(\mathbf{1 0 0})$ & $\mathbf{2 5 ( 1 0 0 )}$ & $\mathbf{9 0}$ \\
\hline
\end{tabular}

Markers and histological grade: Among 72 cases of endometrioid carcinoma, those with grade I expressed estrogen receptors (26 out of 34 cases - 72\%) more frequently than those with grades II and III. Frequency of p53 positivity was significantly higher at higher grades (Table 3).

Table 2: p53 and estrogen receptor expression and histological type of endometrial carcinoma.

\begin{tabular}{|lcll|}
\hline Stage & $\begin{array}{c}\text { Endometrioid } \\
\text { type n (\%) }\end{array}$ & $\begin{array}{l}\text { Non endometrioid } \\
\text { type n }(\%)\end{array}$ & $\begin{array}{l}\text { In } \\
\text { total }\end{array}$ \\
\hline I & $26(40 \%)$ & $10(40 \%)$ & 36 \\
\hline II. III. IV & $39(60 \%)$ & $15(60 \%)$ & 54 \\
\hline In total & $\mathbf{6 5}(\mathbf{1 0 0})$ & $\mathbf{2 5 ( 1 0 0 )}$ & $\mathbf{9 0}$ \\
\hline
\end{tabular}

$\mathrm{p}=$ significance by Fisher Exact test.

Markers and final disease stage: p53 expression was observed in $8(22.2 \%)$ tumors in stage I and in 17 $(31.5 \%)$ tumors in stage II, III and IV. We observed increased p53 frequency in the advanced stages.

Table 3: p53 and estrogen receptor expression and histological grade of endometrioid carcinoma.

\begin{tabular}{|llllll|}
\hline & Grade I $(\mathbf{N} \%)$ & Grade II $(\mathbf{N} \%)$ & Grade III (N\%) & In total & P \\
\hline p53 & $2 / 34(5.8 \%)$ & $3 / 26(11.5 \%)$ & $5 / 7(71.4 \%)$ & $10 / 67(14.9 \%)$ & $<0.001$ \\
\hline Estrogen receptors & $26 / 34(76.5 \%)$ & $14 / 26(53.8 \%)$ & $4 / 7(57 \%)$ & $44 / 67(65.7 \%)$ & 0.172 \\
\hline
\end{tabular}
$\mathrm{p}=$ significance by Fisher Exact test.

Table 4: p53 and estrogen receptor expression and endometrial carcinoma stage.

\begin{tabular}{|lllll|}
\hline & Stage I (N\%) & Stage II, III or IV (N\%) & In total & P \\
\hline p53 & $8 / 36(22.2 \%)$ & $17 / 54(31.5 \%)$ & $25 / 90(27.7 \%)$ & 0.034 \\
\hline Estrogen receptors & $21 / 36(58.3 \%)$ & $28 / 54(51.8 \%)$ & $49 / 90(54.4 \%)$ & 0.239 \\
\hline
\end{tabular}

$\mathrm{p}=$ significance by Fisher Exact test.

The presence of estrogen receptors had in 21 patients $(51.2 \%)$ in stage I and 28 patients in stage II, II and IV (Table 4).

\section{DISCUSSION}

Current concepts of endometrial carcinoma successfully integrate traditional histopathology with pathogenetic mechanisms. For a long time, endometrial carcinoma has been classified into two major divisions (types I and II) based on light microscopic appearance, clinical behavior, cancer genesis and epidemiology. ${ }^{26}$ Type I, those with endometrioid histology, comprise $80 \%$ to $90 \%$ of newly diagnosed cases of endometrial carcinoma in the United States. ${ }^{1}$ They are associated with unopposed estrogen exposure and are often preceded by premalignant disease. In contrast, type II endometrial carcinoma have nonendometrioid histology (usually papillary serous or clear cell) with an aggressive clinical course..$^{3,27,28}$ While most non-endometrioid (type II) carcinoma contain mutations of p53, endometrioid (type I) carcinoma demonstrate larger numbers of genetic changes in which the temporal sequence of mutation, and the final combination of defects differ substantially between individual examples. ${ }^{6}$ The overall rate of p53 positivity in our study was found in $13.8 \%$ of the endometrioid and in $68 \%$ of the nonendometrioid carcinoma. Our study demonstrated that frequency of p53 overexpression rises with histological grade. Conversely, estrogen receptors are more frequently positive in endometrioid carcinoma, particularly if welldifferentiated, as reported by others. ${ }^{29}$ Our findings suggest that p53 expression is inversely related to that of estrogen receptors, thus indicating a dual theory of carcinogenesis in the endometrium. ${ }^{15}$ It has been reported that p53 expression correlates with more advanced stages. Although we found slightly greater p53 expression in stages II and III, observed difference was not statistically significant. This finding is in agreement with the findings of other researchers, such as Doll et al. ${ }^{24}$ The estrogen receptors were more frequent in the endometrioid type tumors with regard to tumors of the non-endometrioid type, what was expected considering previously mentioned fact that hormonal risk factors have not been identified, and there is no readily observed premalignant phase in cases of non-endometrioid carcinomas. 


\section{CONCLUSION}

Using $80 \%$ of cells as threshold for p53 positivity, we confirmed that p53 staining is common characteristic of non-endometrioid endometrial carcinoma. Moreover, regarding endometrioid type carcinoma, the like hood of positive p53 staining is dramatically increasing with tumour grade, which imply that p53 staining is marker of high-grade endometrial carcinomas: high grade endometrioid and non-endometrioid carcinomas, that are in each case considered high grade.

Lack of p53 positivity is more common finding in patients diagnosed with stage I than in patients diagnosed in later stages.

Using $1 \%$ of cells as threshold for ER positivity, we confirmed that ER are common in endometrioid type carcinoma, in contrast to non-endometrioid type. Although observed, higher frequency of ER in tumors with lower grade and stage was not statistically confirmed in our study population.

Funding: No funding sources

Conflict of interest: None declared

Ethical approval: The study was approved by the Institutional Ethics Committee

\section{REFERENCES}

1. American Cancer Society. Cancer Facts and Figures 2019. Atlanta: American Cancer Society; 2019 Available at: https://www.cancer.org/content /dam/cancer-org/research/cancer-facts-and-statistics /annual-cancer-facts-and-figures/2019/cancer-factsand-figures-2019.pdf. Accessed on $20^{\text {th }}$ October 2019.

2. Kurman RJ, Carcangiu ML, Harrington CS, Young $\mathrm{RH}$, eds. WHO Classification of Tumors of the Female Reproductive Organs. Geneva, Switzerland: WHO Press; World Health Organization Classification of Tumors. 4th ed.; 2014:275-278.

3. Ellenson L, Ronnett BM, Kurman RJ. Endometrial carcinoma. In: Kurman RJ, Ellenson L and Ronnett BM, editors. Blauestein's Pathology of the Female Genital Tract. 6th edition. New York: SpringerVerlag; 2011:393-452.

4. Ryan AJ, Susil B, Jobling TW, Oehler MK. Endometrial cancer. Cell Tissue Res. 2005;322:5361.

5. Moore KN1, Fader AN. Uterine papillary serous carcinoma. Clin Obstet Gynecol. 2011;54(2):278-91.

6. Sherwin R, Catalano R, Sharkey A. Large-scale gene expression studies of the endometrium: what have we learnt? Reprod. 2006;132:1-10.

7. Shiozawa T, Konishi I. Early endometrial carcinoma: clinicopathology, hormonal aspects, molecular genetics, diagnosis and treatment. The International J Clin Oncol. 2006;11:13-21.
8. Sankaranarayanan R, Ferley J. Worldwide burden of gynecological cancer: the size of problem. Best Pract Res Clin Obstet Gynecol. 2006;20:207-25.

9. Pearce ST, Jordan VC. The biological role of estrogen receptors $\alpha$ and $\beta$ in cancer. Crit Rev Oncol/Hematol. 2004;50:3-22.

10. Gehrig PA, Van Le L, Olatidoye B, Geradts J. Estrogen receptor status, determined by immunohistochemistry, as a predictor of the recurrence of stage I endometrial carcinoma. Cancer. 2009;86(10):2083-89.

11. Kounelis S, Kapranos N, Kouri E, Coppola D, Papadaki H, Jones MW. Immunohistochemical profile of endometrial adenocarcinoma: a study of 61 cases and review of the literature. Mod Pathol. 2008;13(4):379-88.

12. Oreskovic S, Babic D, Kalafatic D, Barisic D, Beketic Oreskovic L. A significance of immunohistochemical determination of steroid receptors, cell proliferation factor $\mathrm{Ki}-67$ and protein p53 in endometrial carcinoma. Gynecol Oncol. 2004;93(1):34-40.

13. Ryan AJ, Susil B, Jobling TW, Oehler MK. Endometrial cancer. Cell Tissue Res. 2005;322:5361.

14. Bozdogan O, Atasoy P, Erekul S, Bozdogan N, Bayram M. Apoptosis- related proteins and steroid hormone receptors in normal, hyperplastic, and neoplastic endometrium. Int $\mathbf{J}$ Gynecol Pathol. 2008;21:375-82.

15. Engelsen IB, Akslen LA and Salvesen HB. Biologic markers in endometrial cancer treatment. APMIS. 2009;117(10):693-707.

16. Stavropoulos A, Varras M, Vasilakaki T. Expression of p53 and PTEN in human primary endometrial carcinomas: Clinicopathological and immunohistochemical analysis and study of their concomitant expression. Oncol Lett. 2019;17(5):4575-89.

17. Köbel M, Ronnett BM, Singh N, Soslow RA, Gilks $\mathrm{CB}$, McCluggage WG. Interpretation of P53 Immunohistochemistry in Endometrial Carcinomas: Toward Increased Reproducibility. Int J Gynecol Pathol. 2019;38 (1):S123-S131.

18. Debra A. Budwit-Novotny, Kenneth S. Immunohistochemical analyses of estrogen receptor in endometrial adenocarcinoma using a monoclonal antibody. Cancer Res. 1986;46(10):5419-25.

19. Heinonen PK, Isola J, Kuoppala T. Immunohistochemical determination of estrogen and progesterone receptors and DNA flow cytometry in endometrial cancer. Int $\mathrm{J}$ Gynecol Cancer. 1994;4(3):169-73.

20. McCarty KS Jr, Miller L, Cox EB, Konrath J, McCarty KS Sr. Estrogen receptor analyses: correlation of biochemical and immunohistochemical methods using monoclonal antire- ceptor antibodies. Arch Pathol Lab Med. 1985;109:716-21.

21. Goswami S, Sen A, Biswas M. Association of the hormonal receptor status of endometrial carcinomas 
with the markers of tumor aggression: A comparison with similar studies in developed nations. Med J DY Patil Univ. 2017;10:334-8.

22. Waqar S, Khan SA, Sarfraz T, Waqar S. Expression of estrogen receptors (ER), progesterone receptors (PR) and HER-2/neu receptors in Endometrial Carcinoma and their associations with histological types, grades and stages of the tumor. Pak J Med Sci. 2018;34(2):266-71.

23. Hammond ME, Hayes DF, Dowsett M, Allred DC, Hagerty KL, Badve S, et al. American Society of Clinical Oncology/College of American Pathologists guideline recommendations for immunohistochemical testing of estrogen and progesterone receptors in breast cancer (unabridged version). Arch Pathol Lab Med. 2010;134(7):e48-72.

24. Doll A, Abal M, Rigau M, Monge M, Gonzalez M, Demajo S, et al. Novel molecular profiles of endometrial cancer-new light through old windows. J Steroid Biochem Mol Biol. 2008:108(3-5):221-9.

25. Feng YZ, Shiozawa T, Miyamoto T, Kashima H, Kurai $\mathrm{M}$, et al. BRAF mutation in endometrial carcinoma and hyperplasia: correlation with KRAS and p53 mutations and mismatch repair protein expression. Clin Cancer Res. 2005;11(17):6133-8.

26. Bockman JV. Two pathogenic types of endometrial carcinoma. Gynecol Oncol. 1983;15:10-7.

27. Felix AS, Weissfeld JL, Stone RA. Factors associated with Type I and Type II endometrial cancer. Cancer Causes Cont. 2010;21(11):1851-6.

28. Esteller M, Xercavins J, Reventos J. Advances in the molecular genetics of endometrial cancer. Oncol Rep. 1999;6:1377-82.

29. Uharcek P. Prognostic factors in endometrial carcinoma. J Obstat Gynaecol Res. 2008;34(5):77683.

Cite this article as: Opric D, Suskic A, Suskic SH, Nikolic G, Filipovic I. Value of p53 and estrogen receptors immunohistochemical staining in endometrial carcinoma. Int J Reprod Contracept Obstet Gynecol 2019;8:4885-90. 